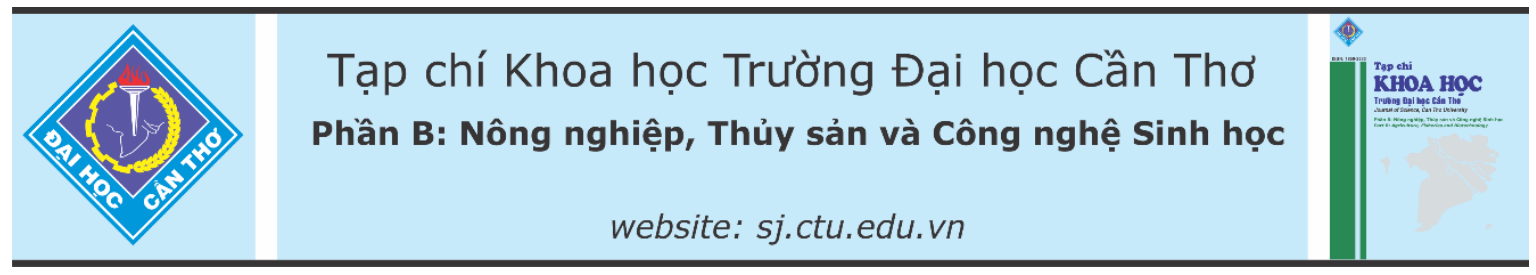

DOI:10.22144/ctu.jvn.2021.096

\title{
ẢNH HƯỞNG CỦA VÙNG SINH THÁI ĐẾN TÍNH TRẠNG CHÂT LƯợNG CỦA 20 GIỐNG LÚA RÃ̃Y
}

Chung Trương Quốc Khang, Huỳnh Như Điền, Lê Thị Hồng Thanh, Nguyễn Văn Mạnh, Trần In Đô, Phạm Thị Bé Tư, Văn Quốc Giang, Nguyễn Châu Thanh Tùng, Nguyễn Lộc Hiền và Huỳnh Kỳ ${ }^{*}$

Bộ môn Di truyền và Chọn giống Cây trồng, Khoa Nông nghiệp, Truờng Đại học Cần Tho

*Nguoòi chịu trách nhiệm về bài viết: Huỳnh Kỳ (email: hky@ctu.edu.vn)

\section{Thông tin chung:}

Ngày nhận bài: 07/01/2021

Ngày nhận bài sưa: 29/01/2021

Ngày duyệt đăng: 25/06/2021

\section{Title:}

Effects of ecological zone on rice quality among 20 upland rice varieties

\section{Tù khóa:}

Amylose, chất lượng, chiều dài gạo, lúa rẫy, vùng sinh thái

\section{Keywords:}

Amylose, ecological zone long grain, quality, upland rice

\begin{abstract}
Agro-ecological conditions in Vietnam are quite diverse. This is an advantage for the development of different rice varieties to create a specific characteristic of each region. To improve the diversity of rice genetics resource, 20 upland rice were used to characterize the quality of rice including length grain, amylose contents, and aroma when they were plantted in two contrast ecological zones (1) Buon Ma Thuot province (highland); (2) Tra Vinh province (Mekong Delta) in this study. The results showed that These varieties cultivated in Tra Vinh were showed long gain and amylose content (80\% and $60 \%$, respectively) characteristics higher than in Buon Ma Thuot. In addition, 6 rice varieties were selected because of its high-quality characteristics such as long grain, low and medium amylose contents. While, two varieties Ba Bo Nha and Ba Hlang were suitable cultivated in both regions, Buon Me Thuoc and Tra Vinh. Mean while Ba Ie and Pkoih (aroma) were more suitable for planting in Tra Vinh, but Nâm and Ba Kong Brum varieties were better for planting in Buon Ma Thuot. The results of this study will provide quality rice genetic resources for 2 ecological zone including highland and Mekong Delta of Viet Nam.
\end{abstract}

\section{TÓM TẮT}

Sinh thái nông nghiệp ở Việt Nam khá đa dạng, đây là một uu thế cho sư phát triển các giống lúa khác nhau tạo nên đặc trung riêng của tùng vùng. Nhằm đa dạng nguồn gen, trong nghiên cưu này, 20 giống lúa rẫy được thu thập tại các tỉnh thuộc vùng Tây Nguyên làm vật liệu và tiến hành phân tích, so sánh sự khác nhau của môt số chỉ tiêu chất lượng: chiều dài hạt, amylose, mùi thơm khi được trồng tại hai vùng sinh thái là tỉnh Buôn Ma Thuôt (Tây Nguyên) và tỉnh Trà Vinh (Đồng bằng sông Cưu Long). Kết quả ghi nhận đa số các giống lúa được trồng tại Trà Vinh đều có chiều dài hạt gạo dài (80\% giống) và hàm luợng amylose (60\% giống) cao hơn khi được trồng tại Buôn Ma Thuột. Bên cạnh đó, nghiên cứu cũng đã tuyển chọn được 6 giống lúa đều thuộc nhóm lúa hạt dài, mềm cơm, dẻo. Trong đó, 2 giống Ba Bơ Nhã và Ba Hlang thich hợp trồng ở cả hai vùng sinh thái; 2 giống lúa canh tác ở Trà Vinh là giống Ba Ĩe và giống Pkoih (lúa thơm); đối với vùng Buôn Ma Thuột có thể sư dụng 2 giống là Nâm và Ba Kong Brum. Kết quả thí nghiệm này là bước đầu có thể cung cấp nguồn gen lúa chất luợng cho 2 vùng sinh thái Tây Nguyên và Đồng bằng sông Cưu Long. 


\section{1. ĐẶT VẤN ĐỀ}

Lúa là cây lương thực chính cho trên $50 \%$ dân số trên toàn thế giới, cơ bản cung cấp khoảng $50 \%$ $80 \%$ năng lượng hằng ngày (Kromdijk and Long, 2016; Shamim, 2018). Do đó, nhu cầu về gạo chất lượng rất cao và đặc tính chất lượng ở gạo được quyết định bởi đặc tính vật lý, hóa lý và một số thành phần liên quan khác. Một trong 3 đặc tính liên quan đến chất lượng được quan tâm là độ mềm cơm nấu (liên quan đến thành phần amylose trong hạt gạo) và mùi thơm (Custodio et al., 2019). Vì vậy, việc tìm nguồn gen mang 3 đặc tính trên bổ sung nguồn gen luôn là cần thiết cho việc phát triển lúa vùng Đồng bằng sông Cửu Long (ĐBSCL). Hiện nay một phần nhỏ diện tích lúa ở Việt Nam cũng được canh tác vùng Tây Nguyên chủ yếu là lúa rẫy và chúng chưa được khai thác. Đặc tính của lúa rẫy (lúa vùng cao) thường được trồng trên các sườn dốc, độ dốc đất thay đổi từ 0 đến hơn $30 \%$, chiếm khoảng $11 \%$ sản lượng lúa toàn cầu (Tuhina-Khatun et al., 2015), trong đó khoảng 13 triệu ha trồng ở châu Á (Acuña et al., 2008), cung cấp lương thực cho người dân sống ở vùng đất khô cằn (Suwarno et al., 2009). Do đó, việc khai thác đánh giá đa dạng di truyền và bổ sung nguồn gen lúa rẫy cho vùng ĐBSCL là rất là cấp thiết.

Thực vậy, đa dạng di truyền là cơ sở của chọn tạo giống cây trồng, vì vậy hiểu và đánh giá nó có ý nghĩa quan trọng đối với việc quản lý cây trồng, cải tạo cây trồng bằng cách chọn lọc, sử dụng nguồn gen cây trồng, phát hiện cấu trúc bộ gen và chuyển các tính trạng mong muốn cho các cây khác (Sasaki and International Rice Genome Sequencing, 2005; Varshney et al., 2008). Do đó, việc nghiên cứu đặc điểm đa dạng di truyền của lúa rẫy vùng Tây Nguyên để bổ sung những tính trạng tốt cho lúa vùng ĐBSCL là rất hữu ích. Theo quan sát, đặc điểm chính của lúa rẫy là cây cao, lá phát triển mạnh, cạnh tranh cao với cỏ dại, rễ dài đâm sâu vào đất để sử dụng nguồn nước ngầm. Nhiều giống lúa rẫy nặng hạt, hàm lượng amylose từ thấp đến trung bình, nhiệt trở hồ và độ bền thể gel trung bình và đã được đánh giá cao về chất lượng, cơm nấu ngon và mức giá cao trên thị trường (Greenland, 1985). Ngoài ra, đặc điểm nổi bật nhất ở lúa rẫy là tính phản ứng với ánh sáng ngày ngắn, giống lúa rẫy chỉ phân hóa đòng khi thời gian chiếu sáng trong ngày thấp hơn 12 giờ 30 phút (Kawamura et al., 2020). Gạo lúa rẫy thường thơm, cây chín muộn, được trồng hữu cơ, ít được quản lý và chăm sóc dẫn đến năng suất lúa thấp (Atlin et al., 2006).

Ở Việt Nam, lúa rẫy được trồng chủ yếu ở Tây Nguyên, nhưng hiện nay do người dân khu vực thay đồi canh tác từ trồng lúa sang các loại cây trồng khác, nên diện tích lúa rẫy ngày càng bị thu hẹp, ít được nghiên cứu và nguy cơ mất đi các đặc tính đặt trưng ở các giống lúa địa phương. Một trong những đặc tính rất quan trọng ở lúa rẫy cần được khai thác và bổ sung nguồn gen cho lúa vùng ĐBSCL là tính trạng chất lượng. Trên cơ sở đó, thí nghiệm được thực hiện nhằm khảo sát đặc tính di truyền và chất lượng của 20 giống lúa rẫy được trồng ở $2 \mathrm{khu}$ vực Tây Nguyên và ĐBSCL, nhằm tìm ra nguồn gen lúa rẫy có khả năng khai thác và phát triển ở vùng ĐBSCL. Kết quả nghiên cứu này là cung cấp những thông tin hữu ích vê việc khai thác và phát triển nguồn gen lúa rẫy trong tương lai.

\section{VÂT LIÊU VÀ PHƯƠNG PHÁP NGHIỀ CÚU}

\subsection{Vật liệu nghiên cứu}

Thí nghiệm được thực hiện trên 20 giống lúa rẫy (Bảng 1 ), nguồn giống sử dụng từ $\mathrm{Ngân}$ hàng giống thuộc Bộ môn Di truyền và Chọn giống cây trồng, Khoa Nông nghiệp, Trường Đại học Cần Thơ. 
Bảng 1. Danh sách lúa rẫy và nguồn gốc lúa

\begin{tabular}{cll}
\hline STT & Tên giống & Nguồn gốc \\
\hline 1 & Ba Bơ Nhã & Dektu, Kon Dơng, Mang Yang, Gia Lai \\
2 & Ba Chăm & Khôn Lương, Krong, K’Bang, Gia Lai \\
3 & Ba Cõng & Hle Hlang, Yang Trung, Kông Chro, Gia Lai \\
4 & Ba Cong & Măng, Ya Ma, Gia Lai \\
5 & Ba Ĩe & Hle Hlang, Yang Trung, Kông Chro, Gia Lai \\
6 & Ba Hlang & Kon Thụp. Mang Yang, Gia Lai \\
7 & Ba Jirui & Kon Thụp. Mang Yang, Gia Lai \\
8 & Ba Kieng & Kon Thụp. Mang Yang, Gia Lai \\
9 & Ba Kong Brun & Đăk Sơ Mei, Đăk Đoa, Gia Lai \\
10 & Cbr & Canh Hòa, Vân Canh, Bình Định \\
11 & Chăm & La Tul, La Pa (huyện Ayun Pa cũ), Gia Lai \\
12 & Cham muan & Quen, H'bông, Chư Sê, Gia Lai \\
13 & Geh Gor Lao & Briêng, La Boòng, Chư Prông, Gia Lai \\
14 & Gor & Chu Ruôi, Dun, Chư Sê, Gia Lai \\
15 & Grô Dlông & Hliêt, Chư Răng (Chư Đrăng) \\
16 & Kreng & Giam, La Kha, La Grai, Gia Lai \\
17 & Mơ Dai Kroăi & Hliêt, Chư Răng (Chư Đrăng), Krông Pa, Gia Lai \\
18 & Nâm & Kép, La Kha, La Grai, Gia Lai \\
19 & Pkoih & Hà Vắc 1, Ayun, Chư Sê, Gia Lai \\
20 & Se Gon & Tnao, La Boòng, Chư Prông, Gia Lai \\
\hline
\end{tabular}

\subsection{Phương pháp nghiên cứu}

\subsubsection{Thời gian và địa điểm nghiên cưu}

Thí nghiệm thực hiện từ tháng 6/2019 đến tháng $5 / 2020$. Lúa được trồng, thu mẫu tại xã Ea Kao, Tp. Buôn Ma Thuột (BMT), tỉnh Đắk Lắk và xã Phong Phú, huyện Cầu Kè, tỉnh Trà Vinh (TV). Các phân tích được tại Bộ môn Di truyền và Chọn giống cây trồng, Khoa Nông nghiệp, Trường Đại học Cần Thơ.

\subsubsection{Phuoong pháp nghiên cúu}

Hàm lượng amylose được xác định theo phương pháp của (Juliano, 1971). Hàm lượng amylose được đánh giá theo thang điểm IRRI (Bảng 2).

Bảng 2. Phân loại theo hàm lượng amylose trong hạt (IRRI, 1996)

\begin{tabular}{cll}
\hline $\begin{array}{c}\text { Hàm lượng } \\
\text { Amylose (\%) }\end{array}$ & Đánh giá & Phân loại gạo \\
\hline $0-5$ & Nếp & Nếp \\
$5,1-12$ & Gạo dẻo & Rất thấp \\
$12,1-20$ & Gạo dẻo & Thấp \\
$20,1-25$ & Mềm cơm & Trung bình \\
$>25$ & Cứng cơm & Cao \\
\hline
\end{tabular}

Đánh giá cảm quan mùi thơm: 40 hạt gạo loại bỏ vỏ cám được sử dụng để đánh giá mùi thơm, gạo được ngâm bằng $10 \mathrm{ml}$ dung dịch $\mathrm{KOH} \mathrm{1,7 \%} \mathrm{trong}$ đĩa petri trong 1 giờ (Faruq et al., 2010). Sau đó, mẫu được đánh giá cảm quan theo thang điểm đánh giá của IRRI (Bảng 3), số người tham gia đánh giá là 10 người.

Bảng 3. Thang điểm đánh giá cảm quan mùi thom (IRRI, 1996)

\begin{tabular}{cl}
\hline Thang điểm & Mùi thơm \\
\hline 0 & Không thơm \\
1 & Thơm nhẹ \\
2 & Thơm \\
\hline
\end{tabular}

\section{Phân tích đặc tính di truyền:}

Ly trích DNA từ mô lá bằng phương pháp sử dụng CTAB (Cetyl Trimethyl Ammonium Bromide) của Doyle (1990).

Phân tích mùi thơm, chiều dài hạt gạo (Ramkumar et al., 2010), waxy A-C (Zhou et al., 2018) và $\mathrm{G}-\mathrm{T}$ (Cai et al., 2015b) bằng chỉ thị phân tử tương ứng được tổng hợp bởi công ty Sinh hóa Phù $\mathrm{Sa}$ (Việt Nam) sử dụng khuếch đại DNA (Bảng 4). 
Bảng 4. Trình tự đoạn mồi sử dụng trong thí nghiệm

\begin{tabular}{|c|c|c|c|}
\hline Primer & Trình tụ̣ $5^{\prime} \rightarrow 3^{\prime}$ & Sản phẩm & $\begin{array}{l}\text { Chiều dài } \\
\text { band (bp) }\end{array}$ \\
\hline \multicolumn{4}{|c|}{ Mồi nhận diện Waxy A-C (Zhou et al., 2018). } \\
\hline $\begin{array}{l}\text { Ex6AF } \\
\text { Ex6AR }\end{array}$ & $\begin{array}{l}\text { CTGGAGAAGGTGGAGTCAT } \\
\text { GATCTTGAGATCAATTGTAACTCACGAT }\end{array}$ & AF-CR (Common band) & 1025 \\
\hline Ex6CF & CAACCCATACTTCAAAGGAACATC & AF-AR (A type) & 310 \\
\hline Ex6CR & GGCGGTGATGTACTTGTCC & CF-CR (C type) & 766 \\
\hline \multicolumn{4}{|c|}{ Mồi nhận diện Waxy G-T (Cai et al., 2015b). } \\
\hline $\begin{array}{l}\text { WxGF } \\
\text { WxGR }\end{array}$ & $\begin{array}{l}\text { TACAAATAGCCACCCACA } \\
\text { GGGAAACAAAGAATTATAAACATATATGTACAC }\end{array}$ & $\mathrm{R}$ (Common band) & 387 \\
\hline WxTF & CATCAGGAAGAACATCTGCAAGT & GF-GR (G type) & 207 \\
\hline WxTR & GATCAGCCTAACCAAACA & TF-TR (T type) & 235 \\
\hline \multicolumn{4}{|c|}{ Mồi nhận diện mùi thơm (Bradbury et al., 2005) } \\
\hline $\begin{array}{l}\text { EAP } \\
\text { ESP }\end{array}$ & $\begin{array}{l}\text { AGTGCTTTACAAAGTCCCGC } \\
\text { TTGTTTGGAGCTTGCTGATG }\end{array}$ & ESP-EAP (Common band) & 580 \\
\hline INSP & TGGTAAAAAGATTATGGCTTCA & ESP-IFAP (Aroma) & 257 \\
\hline IFAP & CATAGGAGCAGCTGAAATATATACC & EAP-INSP (Non- aroma) & 355 \\
\hline \multicolumn{4}{|c|}{ Mồi nhận diện chiều dài hạt gạo (Ramkumar et al., 2010). } \\
\hline EFP & AGGCTAAACACATGCCCATCTC & \multirow{2}{*}{ EFP-ERP (Common band) } & \multirow{2}{*}{365} \\
\hline ERP & CCCAACGTTCAGAAATTAAATGTGCTG & & \\
\hline IRSP & AACAGCAGGCTGGCTTACTCTCTG & EFP-IRSP (short) & 147 \\
\hline IFLP & ACGCTGCCTCCAGATGCTGA & ERP-IFLP (long) & 262 \\
\hline
\end{tabular}

\subsubsection{Phuoong pháp xủ lý số liệu}

Số liệu thống kê và biểu đồ được phân tích bằng phần mềm Microsoft Excel 2016, sử dụng phép kiểm định Tukey HSD trên phần mềm thống kê Statgraphics và Origin 2017.

\section{KẾT QUẢ VÀ THẢO LUẬN}

\section{1. Điều kiện môi trường ảnh hưởng đến chiều dài hạt gạo}

Chiều dài hạt gạo được quyết định bởi kiểu gen (Hình 1B), nhưng chịu ảnh hưởng bởi điều kiện môi trường sinh thái, vùng sinh thái Trà Vinh có chiều dài hạt dài hơn vùng sinh thái Buôn Ma Thuột (Hình 1C). Nhìn chung, kiểu gen của giống Ba Kieng có chiều dài hạt dài nhất $(7,84 \mathrm{~mm})$, Cbr và Grô Dlông có chiều dài hạt ngắn nhất $(6,12 \mathrm{~mm}$ và $5,98 \mathrm{~mm})$ (Hình 1B). Qua đó, điều kiện môi trường sinh thái ở TV thuận lợi cho các giống lúa đạt được chiều dài hạt gạo dài hơn cùng giống khi trồng ở BMT (16 giống ở TV có chiều dài hạt dài hơn $\mathrm{BMT}$ ). Ở TV, giống $\mathrm{Ba}$ Kieng, Pkoih thuộc nhóm hạt rất dài. Nhóm hạt dài gồm $\mathrm{Ba}$ Bơ Nhã, Ba Chăm, Ba Cõng, Ba Cong, Ba Îe, Ba Hlang, Ba Jirui, Ba Kieng, Ba Kong Brun, Chăm, Cham Muan, Geh Gor Lao, Gor, Mơ Dai Kroăi, Nâm và Se Gon, trồng thích hợp ở TV. Còn lại các giống có chiều dài hạt trung bình, không có giống nào ngắn hạt (Hình 1D). Vì vậy, đa số các giống lúa trong nhóm có chiều dài $>7 \mathrm{~mm}$ sẽ được thị trường ưa chuộng, còn các giống ngắn hạt sẽ gặp khó khăn khi xuất khẩu. Ở BMT, giống Ba Kieng xếp vào nhóm hạt rất dài. Các giống $\mathrm{Ba} B o ̛$ Nhã, Ba Chăm, Ba Cõng, Ba Cong, Ba Ĩe, Ba Hlang, Ba Jirui, Ba Kong Brun, Chăm, Cham Muan, Geh Gor Lao, Gor, Mơ Dai Kroăi, Nâm, Pkoih, Se Gon thuộc dài hạt, thích hợp canh tác ở BMT. Các giống còn lại trung bình, không có giống nào nhóm ngắn hạt (Hình $1 \mathrm{D})$. Như vậy, tùy theo vùng sinh thái khác nhau, có thể chọn giống lúa khác nhau để canh tác nhằm cho kiểu hình hạt gạo dài, ngắn theo mong muốn.

Theo Ramkumar et al. (2010), gen GS3 quy định tính trạng chiều dài hạt gạo cho nên đã thiết lập nên hệ thống dấu phân tử DRR-LG để nhận diện về kiểu gen liên kết với chiều dài hạt gạo. Kết quả ứng dụng dấu phân tử DRR-LG đã nhận diện được 3 giống Ba Cong, Cbr, Grô Dlông khuếch đại được băng hình 147 bp quy định cho tính trạng hạt ngắn. Trong khi đó, 17 giống còn lại khuếch đại được băng hình 262 bp đại diện cho tính trạng hạt dạng dài (Hình 1A). Như vậy kết quả nghiên cứu này phù hợp với kết quả trước cho rằng kiểu hình được thể hiện bởi kiểu gen nhưng chịu tác động bởi điều kiện môi trường, sinh thái (Garrod, 1902; Baye et al., 2011). 


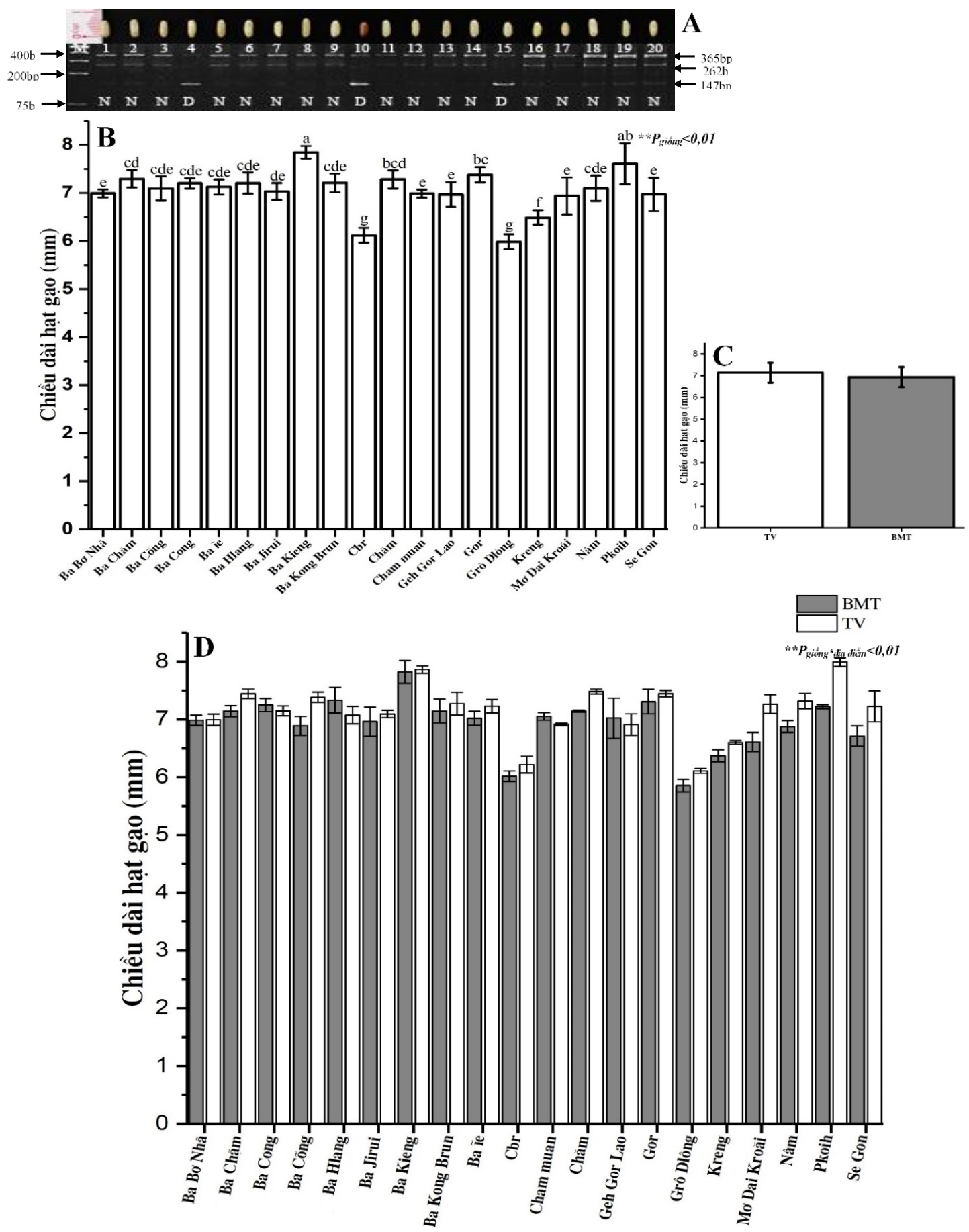

Hình 1. Mối tương quan giữa chất lượng và đặc điểm di truyền chiều dài hạt gạo giữa 2 vùng sinh thái trên 20 giống lúa rẫy

(Các cột có cùng chũ theo sau thì khác biệt không ý nghĩa qua kiểm định Tukey HSD ở mức ý nghĩa **p<0,01; Hình 1A: Phổ điện di nhận diện gen GS3 bằng gel polyacrylamide $8 \%$ M: ladder $1 \mathrm{~kb}$ plus, giếng 1-20 tuoong ứng theo số thư tự Bảng 1, N: hạt ngắn, D: hạt dài; Hình 1B: Chiều dài trung bình hạt gạo 20 giống lúa khảo sát; Hình 1C: Tổng chiều dài trung bình 20 giống lúa ở 2 vùng sinh thái; Hình 1C: Tương quan chiều dài hạt gạo ở 2 vùng khảo sát) 


\section{2. Ảnh hưởng của vùng sinh thái lên hàm lượng amylose (AC) trong hạt}

Quá trình tổng hợp amylose trong gạo được kiểm soát bởi enzym tổng hợp tinh bột liên kết với hạt, được mã hóa bởi gen Waxy (Wx) (Nelson and Rines, 1962). Bằng việc mã hóa các gen chức năng như vậy đã có rất nhiều allen $\mathrm{Wx}$ đã được xác định trong các giống lúa như $W x^{a}$ (Sano, 1984), $W x^{b}$ (Wang et al., 1995), Wi (Mikami et al., 2008). Trong đó, một biến thể của gen $W x$ bị đột biến ở exon số 6 từ kiểu gen C/A đã được Zhou et al. (2018) thiết kế dựa theo phương pháp PCR với 2 cặp mồi đối đầu (PCR$\mathrm{CTPP})$ và đã được sử dụng trong nghiên cứu này. Kết quả khuếch đại bằng cặp mồi Ex6A/C (Hình 2A) vị trí 766 bp xuất hiện ở giống Ba Kong Brun, theo kết quả nghiên cứu primer Ex6A/C khuếch đại band DNA ở 766bp là kiểu C (AC trung bình), các giống còn lại kiểu $\mathrm{A}$ ( $\mathrm{AC}$ cao hoặc thấp) (band 310bp) (Zhou et al., 2018). Thêm vào đó khi phân tích phân tích một biến thể khác tại vị trí +1 ở intron đầu tiên của $W x$, Cai et al. (2015a) cũng đã dùng phương pháp PCR-CTPP để phân biệt biến thể kiểu gen $\mathrm{G}$ hoặc $\mathrm{T}(\mathrm{G} / \mathrm{T})$. Kết quả phân tích dùng cặp primers $\mathrm{WxG} / \mathrm{T}$ (Hình $2 \mathrm{~B}$ ) đã khuếch đại được băng hình 207 bp ở giống $\mathrm{Ba}$ Chăm, Ba Cõng, Ba Cong, Ba Kong Brun, Cbr, Chăm, Grô Dlông, Mơ Dai Kroăi là kiểu $\mathrm{G}$ ( $\mathrm{AC}$ cao). Giống $\mathrm{Ba} \mathrm{Bơ}$ Nhã, $\mathrm{Ba}$ Ĩe, Ba Hlang, Ba Jirui, Ba Kieng, Cham Muan, Geh Gor Lao, Gor, Kreng, Nâm, Pkoih, Se Gon khuếch đại DNA vị trí 235bp mang kiểu T (AC thấp), kết quả này tương tự với nghiên cứu của Cai et al. (2015a). Qua phân tích di truyền gen waxy $\mathrm{A}-\mathrm{C}$ và $\mathrm{G}-\mathrm{T}$ giải thích đúng sự biểu hiện $\mathrm{AC}$ trong 20 giống lúa.

Tương tự như đặc điểm hình thái chiều dài hạt gạo, hàm lượng amylose chứa trong hạt cũng được kiểu gen quyết định (Hình $2 \mathrm{C}$ ), trung bình ở hai vùng sinh thái hàm lượng amylose ở các giống $\mathrm{Ba}$
Chăm và $\mathrm{Ba}$ Cong có $\mathrm{AC}$ cao $(30,73 \%$ và $30,89 \%)$, Ba Jirui $(3,4 \%)$ và Kreng $(2,87 \%)$ là lúa nếp, giống Ba Bơ Nhã, Ba Hlang, Ba Kieng, Cham Muan, Geh Gor Lao, Gor, Pkoih, Se Gon thuộc nhóm gạo dẻo ở cả 2 vùng $(12,1-20 \%)$. Tuy nhiên, hàm lượng amylose chứa trong hạt cũng bị ảnh hưởng bởi điều kiện sinh thái 2 vùng giúp cho hạt gạo tích lũy $\mathrm{AC}$ khác biệt ở ý nghĩa $1 \%$. Tuy nhiên, tùy theo mỗi kiểu gen mà khả năng tích lũy hàm lượng amylose có khác nhau ở mỗi vùng sinh thái như giống Ba Cong, Ba Ĩe, Ba Kieng, Chăm, Cham Muan, Gor, Grô Dlông và Pkoih ở TV có $\mathrm{AC}$ cao hơn $\mathrm{BMT}$. Ngược lại, giống Ba Bơ Nhã, Ba Kong Brun, Geh Gor Lao có hàm lượng amylose trong hạt khi được canh tác ở $\mathrm{BMT}$ cao hơn $\mathrm{TV}$, các giống còn lại có $\mathrm{AC}$ tương đương nhau (Hình $2 \mathrm{E})$. Thêm vào đó, dựa vào bảng phân loại IRRI (1996) thì giống Ba Îe (23\%) ở TV có $\mathrm{AC}$ thuộc nhóm mềm cơm trong khi ở BMT là gạo dẻo (17,74\%), giống Ba Kong Brun (14,98\%), Nâm $(19,97 \%)$ ở TV là nhóm gạo dẻo nhưng ở BMT là mềm cơm $(24,05 \%$ và $21,42 \%)$. Các giống còn lại đều có hàm lượng cao hơn $25 \%$ nên cứng cơm. Qua đó, giống Ba Ĩe trồng ở TV và giống Ba Kong Brun, Nâm trồng ở BMT đáp ứng nhu cầu của người tiêu dùng vì thị trường ưa chuộng các giống lúa có $\mathrm{AC}$ ở mức trung bình từ $20-25 \%$. Khi kết hợp giữa đánh giá kiểu gen thông qua dấu chỉ thị phân tử kết hợp với phân tích sinh hóa kết quả cho thấy đã đánh giá được $80 \%$ đặc điểm hàm lượng amylose trong hạt gạo. Kết quả ứng dụng chỉ thị phân tử có thể nhận diện được $80 \%$ gạo có kiểu gen đột biến $T / G$ phù hợp với nghiên cứu của (Cai et al., 2015a, b), thêm vào đó hàm lượng amylose được tích lũy trong hạt cũng bị ảnh hưởng bởi điều kiện môi trường và phụ thuộc và kiểu gen, phù hợp với nhiều kết quả nghiên cứu trước (Patindol et al., 2014; Zhang et al., 2016; Li et al., 2018). 

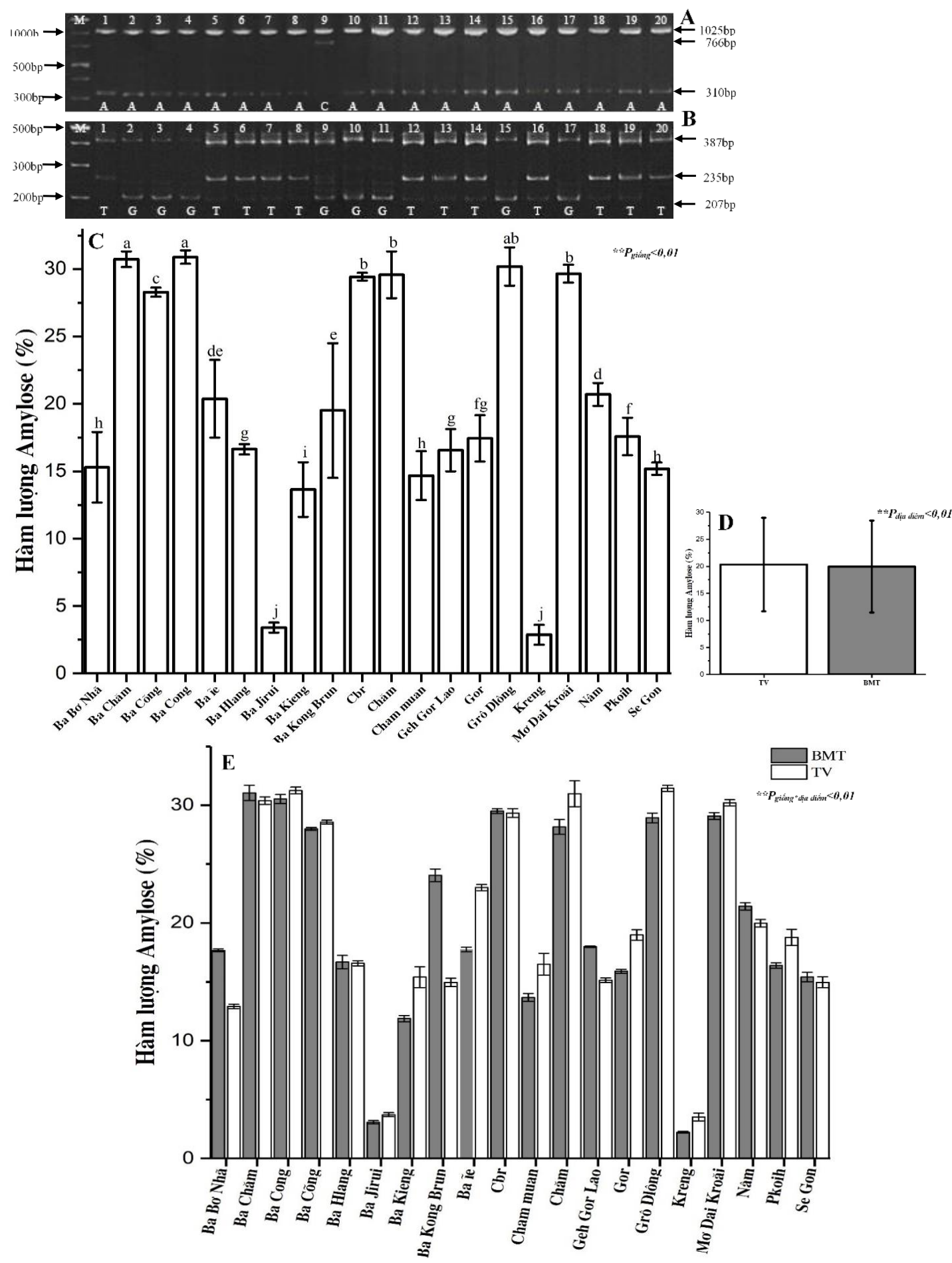

Hình 2. Mối tương quan giữa hàm lượng amylose và gen thơm giữa 2 khu vực

(Các cột có cùng chũ theo sau thì khác biệt không ý nghĩa qua kiểm định Tukey HSD ở múc ý nghĩa **p<0,01; Hình $2 A$ : Phổ điện di nhận diện gen Waxy A-C; Hình $2 B$ : và G-T bằng gel polyacrylamide $8 \%$, M: ladder $1 \mathrm{~kb}$ plus, giếng 1 20 tuoong ứng theo số thứ tụ Bảng 1; Hình 2C: Hàm lượng AC trung bình 20 giống lúa khảo sát; Hình 2D:Tổng hàm luợng AC trung bình 2 vùng khảo sát; Hình 2E: Tưong quan về hàm lượng AC ở 2 vùng khảo sát ) 


\section{3. Đánh giá mùi thơm ở gạo}

Đặc tính mùi thơm trong hạt gạo được điều khiển bởi gen betaine aldehyde dehydrogenase (BADH2), trong đó khi biểu hiện gen $B A D H 2$, làm ức chế sự tổng hợp 2-acetyl-1-pyrroline (2AP), và đây là thành phần chính được tìm thấy khi phân tích mùi thơm của hạt (Buttery et al., 1983). Trên cơ sở đó, phân tích kiểu gen của $B A D H 2$ cho thấy biến thể mất đi 1 đoạn 8 bp ở exon số 7 của gen $B A D H 2$ đã giúp cho cây lúa tổng hợp nên mùi thơm trong hạt, và từ đó bộ dấu phân tử 4 mồi ESP, IFAP, EAP và INSP đã được thiết lập do Bradbury et al. (2005), dùng để nhận diện các giống lúa thơm. Trong nghiên cứu này đã sử dụng và nhận diện được 3 giống $\mathrm{Ba}$ Jirui, Kreng, Pkoih khi khuếch đại được băng hình 257 bp
(Hình 3A), và ngược lại các giống khuếch đại band hình 355 bp chỉ thị giống không thơm. Phân tích di truyền giải thích được $85 \%$ sự biểu hiện mùi thơm của 20 giống lúa.

Theo kết quả phân tích mùi thơm bằng phương pháp KOH của (Faruq et al., 2010) giống Ba Jirui thơm cấp 2 ; giống Pkoil, Kreng, Geh Gor Lao, Ba Hlang, Ba Cõng thơm nhẹ (cấp 1). Các giống lúa còn lại trong bộ giống đều không thơm (Hình 3B). Như vậy, kết quả phân tích kiểu gen đã đánh giá được $85 \%$ so với đánh giá đặc điểm mùi thơm bằng phương pháp sinh hóa. Qua đó, có thể cho thấy Geh Gor Lao, Ba Hlang, Ba Cõng không theo kiểu gen mất 8 bp ở exon 7 của $B A D H 2$.

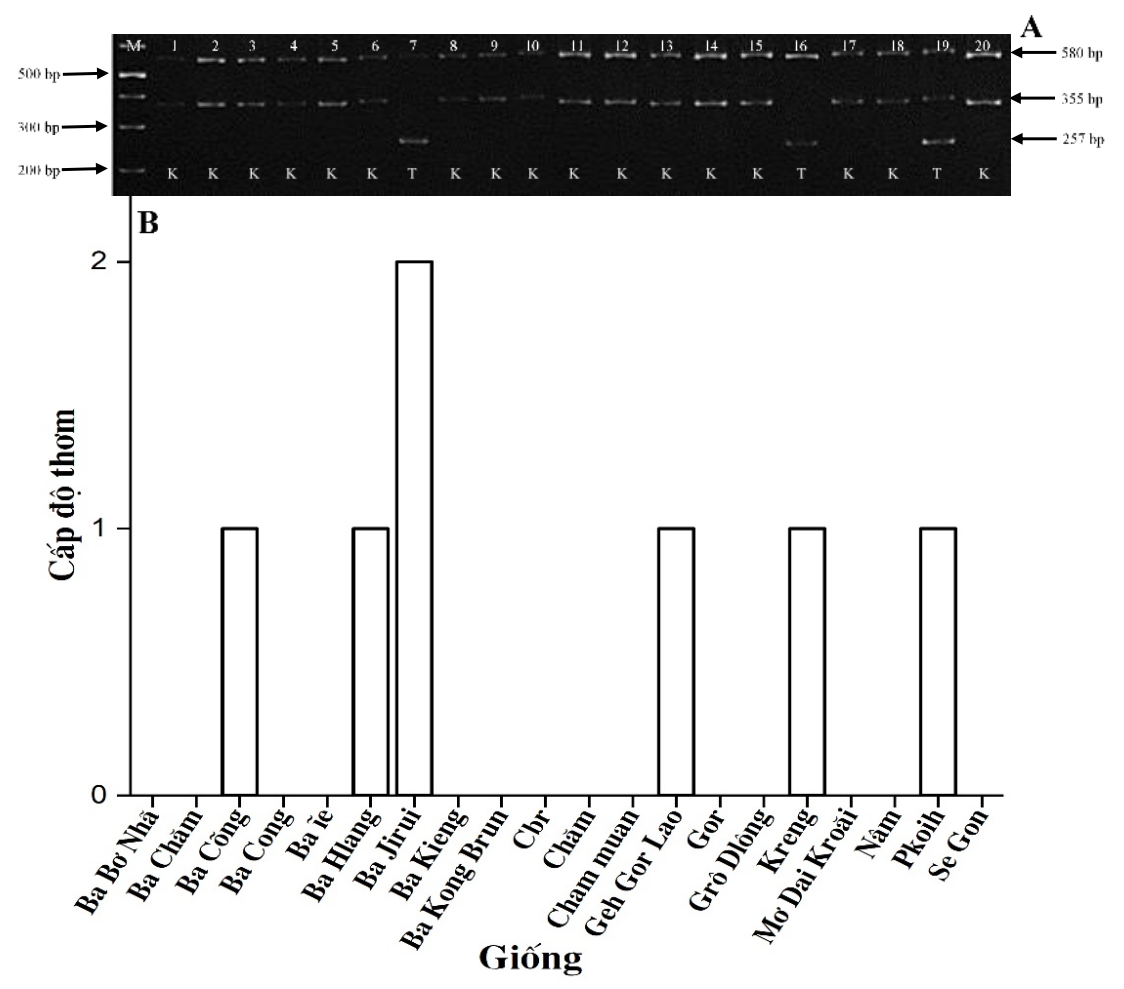

Hình 3. Cảm quan mùi thơm và di truyền phân tử mùi thơm ở lúa

(Hình 3A: Phổ điện di nhận diện gen thơm bằng gel polyacrylamide $8 \%$, M: ladder 1kb plus, giếng 1-20 tuoong úng theo số thứ tư Bảng 1, T: thơm, K: không thơm; Hình 3B: Đánh giá cảm quan mùi thơm trên 20 giống lúa với đối chúng ĐT8 và ST25)

\section{KẾT LUẬn VÀ ĐỀ NGH!}

\subsection{Kết luận}

Tóm lại, khảo sát đặc tính chất lượng của 2 vùng sinh thái của 20 giống lúa rẫy cho thấy vùng sinh thái có thể ảnh hưởng đến đặc tính chiều dài hạt gạo, hàm lượng amylose trong hạt gạo. Mỗi vùng sinh thái phù hợp với đặc tính chất lượng của một số giống. Kết quả đã chọn 6 giống lúa có chất lượng tốt và phù hợp cho từng vùng sinh thái như: giống $\mathrm{Ba}$ Bơ Nhã và Blang có thể canh tác phù hợp cả 2 vùng Tây Nguyên và Trà Vinh. Trong khi đó vùng BMT thì phù hợp cho canh tác giống $\mathrm{Ba}$ Kong Brun và Nâm. Ngược lại ở vùng Trà Vinh giống $\mathrm{Ba}$ Ĩe và Pkoih có tiềm năng phát triển vùng ĐBSCL. 


\section{2. Đề nghị}

Tiến hành khảo sát đánh giá thực tế 2 giống lúa Ba Ĩe và Pkoih ở các vùng sinh thái khác của ĐBSCL, đây là 2 giống lúa có tiềm năng cao về chất lượng có thể phát triển ở ĐBSCL. Ngoài ra, giống Ba Jirui có những đặc tính tốt có thể làm vật liệu di truyền trong công tác chọn tạo giống.

\section{LỜI CẢM TẠ}

Nghiên cứu được tài trợ bởi từ nguồn kinh phí của đề tài nghiên cứu khoa học cấp cơ sở (TĐH2020). Chân thành cám ơn quý Thầy Cô của Viện Nghiên cứu và Phát triển ĐBSCL đã thu thập và bảo tồn nguồn gen lúa rẫy này.

\section{TÀI LIỆU THAM KHẢO}

Acuña, T., Lafitte, H., \& Wade, L. (2008). Genotypexenvironment interactions for grain yield of upland rice backcross lines in diverse hydrological environments. Field Crops Research, 108, 117-125.

Atlin, G.N., Lafitte, H.R., Tao, D., Laza, M., Amante, M., \& Courtois, B. (2006). Developing rice cultivars for high-fertility upland systems in the Asian tropics. Field Crops Research, 97, 43-52.

Baye, T.M., Abebe, T., \& Wilke, R.A. (2011). Genotype-environment interactions and their translational implications. Per Med, 8, 59-70.

Bradbury, L.M.T., Fitzgerald, T.L., Henry, R.J., Jin, Q., \& Waters, D.L.E. (2005). The gene for fragrance in rice. Plant Biotechnology Journal, 3, 363-370.

Buttery, R.G., Ling, L.C., Juliano, B.O., \& Turnbaugh, J.G. (1983). Cooked rice aroma and 2-acetyl-1-pyrroline. Journal of Agricultural and Food Chemistry, 31, 823-826.

Cai, H., Xu, D., Zhou, L., Cheng, J., Zhang, Z., Wu, J., \& You, A. (2015a). Development of PCRbased CNP marker of rice Waxy gene with confronting two-pair primers. Russian Journal of Genetics, 51, 673-676.

Cai, H., Xu, D., Zhou, L., Cheng, J., Zhang, Z., Wu, J., \& You, A. (2015b) . Development of pcr-based snp marker of rice waxy gene with confronting two-pair primers. Genetika, 51, 787-791.

Custodio, M.C., Cuevas, R.P., Ynion, J., Laborte, A.G., Velasco, M.L., \& Demont, M. (2019). Rice quality: How is it defined by consumers, industry, food scientists, and geneticists? Trends in Food Science \& Technology, 92, 122-137.

Doyle, J.J., \& Doyle, J.J. (1990). Isolation of plant DNA from fresh tissue. Focus, 12, 13-15.

Faruq, G., Khalid, N., Harikrishna, J., Bhassu, S., M, Z., Osman, M., abdul majid, N., Zulqarnian, M., \& Mohammad, O. (2010). Evaluation of kernel elongation ratio and aroma association in global popular aromatic rice cultivars in tropical environment. African journal of agricultural research, 5, 1515-1522.

Garrod, A. (1902). The incidence of alkaptonuria : a study in chemical individuality. The Lancet, 160, 1616-1620.

Greenland, D.J. (1985). Upland rice. Outlook on Agriculture, 14, 21-26.

Juliano, B. (1971). A Simplified Assay for Milled-Rice Amylose. Cereal Science Today, 16, 334-360.

Kawamura, K., Asai, H., Yasuda, T., Khanthavong, P., Soisouvanh, P., \& Phongchanmixay, S. (2020). Field phenotyping of plant height in an upland rice field in Laos using low-cost small unmanned aerial vehicles (UAVs). Plant Production Science, 23, 452-465.

Kromdijk, J., \& Long, S.P. (2016). One crop breeding cycle from starvation? How engineering crop photosynthesis for rising $\mathrm{CO}<\mathrm{sub}>2</$ sub $>$ and temperature could be one important route to alleviation. Proceedings of the Royal Society B: Biological Sciences, 283, 20152578.

Li, X., Wu, L., Geng, X., Xia, X., Wang, X., Xu, Z., \& Xu, Q. (2018). Deciphering the Environmental Impacts on Rice Quality for Different Rice Cultivated Areas. Rice (NY), 11, 7-7.

Mikami, A., Hinshaw, S., Patterson, K., \& Lee, J. (2008). Eating Pathology Among Adolescent Girls With Attention-Deficit/Hyperactivity Disorder. Journal of abnormal psychology, 117, 225-235.

Nelson, O.E., \& Rines, H.W. (1962). The enzymatic deficiency in the waxy mutant of maize. Biochemical and biophysical research communications, 9, 297-300.

Patindol, J., Siebenmorgen, T., \& Wang, Y.-J. (2014). Impact of environmental factors on rice starch structure: A review. Starch - Starke, 67.

Ramkumar, G., Sivaranjani, A.K.P., Pandey, M.K., Sakthivel, K., Shobha Rani, N., Sudarshan, I., Prasad, G.S.V., Neeraja, C.N., Sundaram, R.M., Viraktamath, B.C., \& Madhav, M.S. (2010). Development of a PCR-based SNP marker system for effective selection of kernel length and kernel elongation in rice. Molecular Breeding, 26, 735-740.

Sano, Y. (1984). Differential regulation of waxy gene expression in rice endosperm. Theoretical and Applied Genetics, 68, 467-473.

Sasaki, T. (2005). The map-based sequence of the rice genome. Nature, 436, 793-800.

Shamim, M. (2018). Morpho-physiological characterization of aromatic rice (Oryza sativa) genotypes for grain yield under timely sown irrigated condition of upper IGPs. Journal of agrometeorology, 20. 
Suwarno, Lubis, E., Hairmansis, A., \& Santoso. (2009). Development of a Package of 20 Varieties for Blast Management on Upland Rice. In: Wang, G.-L., Valent, B. (Eds.), Advances in Genetics, Genomics and Control of Rice Blast Disease (pp. 347-357). Springer Netherlands, Dordrecht.

Tuhina-Khatun, M., Hanafi, M.M., Rafii Yusop, M., Wong, M.Y., Salleh, F.M., \& Ferdous, J. (2015). Genetic Variation, Heritability, and Diversity Analysis of Upland Rice ( $<\mathrm{i}>$ Oryza sativa $</ \mathrm{i}>$ L.) Genotypes Based on Quantitative Traits. BioMed Research International, 2015, 290861.

Varshney, R.K., Thiel, T., Sretenovic-Rajicic, T., Baum, M., Valkoun, J., Guo, P., Grando, S., Ceccarelli, S., \& Graner, A. (2008).

Identification and validation of a core set of informative genic SSR and SNP markers for assaying functional diversity in barley. Molecular Breeding, 22, 1-13.

Zhang, C., Zhou, L., Zhu, Z., Lu, H., Zhou, X., Qian, Y., Li, Q., Lu, Y., Gu, M., \& Liu, Q. (2016). Characterization of Grain Quality and Starch Fine Structure of Two Japonica Rice (Oryza Sativa) Cultivars with Good Sensory Properties at Different Temperatures during the Filling Stage. Journal of Agricultural and Food Chemistry, 64, 4048-4057.

Zhou, L., Chen, S., Yang, G., Zha, W., Cai, H., Li, S., Chen, Z., Liu, K., Xu, H., \& You, A. (2018). A perfect functional marker for the gene of intermediate amylose content $\mathrm{Wx}$-in in rice (Oryza sativa L.). Crop Breeding and Applied Biotechnology, 18, 103-109. 